\title{
Impact of Mental and Health Promotion on Parents Caring for Children with Cerebral Palsy in Ile-Ife, South-West, Nigeria
}

\author{
Article by Ganiyu Abiodun Adedeji ${ }^{1}$, Caleb Aderemi Adegbenro ${ }^{2}$ \\ ${ }^{I}$ Ph.D. Public Health, Texila American University, Guyana \\ ${ }^{2}$ Ph.D. Public Health, Department of Community Health, College of Health Sciences, \\ Obafemi Awolowo University, Nigeria \\ E-mail: olabode20032001@yahoo.com ${ }^{1}$
}

\begin{abstract}
Background: Studies have shown the correlation between children's physical disabilities and parental stress. The importance of the length of systemic therapy including stress management has also been emphasized in the literature. This study aims to explore the results of a holistic mental and health promotion intervention on parents caring for children with cerebral palsy.

Methods: Self-administered scales (Questionnaires) were employed to measure lifestyle variables, perceived stress, depression and anxiety, locus of control, and spirituality. Prior to commencement of the study, the informed consent of the participants were sought and obtained and ethical clearance was also obtained. A sample size of 80 participants was also calculated for the study. Stress management techniques were taught to the participants in the intervention group who also attended lectures on health behaviors. The control group were placed on normal existing protocol. Odd and even numbers of the participants' birthdate was employed in allocating them to either the intervention or the control groups. The intervention group participated in the health promotion programs for a period of 8 weeks after the pretest measurements. The control group were only placed on the normal existing protocols after the pretest measurements. Both group participants underwent posttest measurements after the 8 week period. Chi-square test was used to determine any significance difference in terms of sociodemographic variables between the two groups. Independent t-test was employed to determine significantt difference between the two groups in relation to mean scores of psychosocial problems after intervention. Paired t-test was also used to determine any significant difference between mean scores of psychosocial problems before and after intervention in the intervention group. Statistical level of significance was set at $P<0.05$.

Results: The results of the independent t-test revealed that the null hypotheses in respect of the anxiety and depression subscales of Depression Anxiety Stress scale (DASS-21) and Perceived Stress Scale (PSS-14) were rejected. Significant difference was found after intervention between groups regarding the anxiety and depression subscales of DASS-21 $(t=4.75, p<0.05)$ and Perceived Stress Scale PSS-14 $(t=-2.76, P<0.05)$. The results of the Chi-Square test showed no significant difference between the groups regarding the sociodemographic variables of the respondents in respect of the participants' sex $\left(X^{2}=1.127, P>0.05\right)$, participants' number of children $\left(X^{2}=1.747, P>0.05\right)$, participants' level of education $\left(X^{2}=3.936, P>0.05\right)$, participants' religion $\left(X^{2}=0.464, P>0.05\right)$ and participants' ethnic groups $\left(X^{2}=3.387, P>0.05\right)$. However the study found significant difference with respect to the participants' marital status $\left(X^{2}=7.014, P<0.05\right)$.

The paired samples t-test showed significant difference between the pre-test and post-test mean scores of the participants' psychosocial problems with regards to the DASS-21 ( $t_{39}=12.758, P<$ $0.05)$ and PSS-14 $\left(t_{39}=79.514, P<0.05\right)$ in the intervention group.

Conclusion: The objectives of this study to reduce the levels of depression, stress and anxiety in parents caring for children with cerebral palsy in Ile-Ife, south-west, Nigeria was achieved. As a result of these achievements, the objective of improving the Quality Of Life (QOL) of the participants was also realized.
\end{abstract}

Keywords: Mental Promotion, Health Promotion, Cerebral Palsy, Parents, Children. 


\section{Introduction}

Cerebral palsy (CP) is a disorder of the central nervous system and it constitutes permanent, nonprogressive anatomical damage of the motor centers of the brain which manifests in impairments in both mobility and posture [20]. It has also been defined as a permanent, but not irreversible impairment of muscle tone and movement which is caused by a damage of the evolving nervous system before or during birth or in the first months of life [7]. Cerebral palsy has been estimated to be five to ten times more common in under-privileged parts of the world, but the exact burden is unknown in most low-and middle-income countries as the global incidence is between 2 and 3 per 1000 live births [16].

As cerebral palsy is the most common cause of physical disability in children worldwide, little is reported on the condition in the African context [4]. A recent study in Egypt [5] reported a childhood prevalence of 3.6 per 1000 live births among children less than or equal to 18 years and 0.4 per 1000 live births among adults aged 19-40 years. Another study from Nigeria [6] which is another developing country in Africa found that birth asphyxia (39.0\%), bilirubin encephalopathy (24.4\%) and post infectious brain damage (18.3\%) were the major causes of cerebral palsy.

A study [13] carried out on psychosocial problems among parents of children with cerebral palsy in Western India revealed a wide range of psychosocial problems that were experienced by the parents of these children. These problems were associated with common themes such as disturbed social relationships, health problems, financial problems, moments of happiness, worries about future of the child, need for more support services and lack of adequate number of trained physiotherapists. Similarly, another study [12] found out that the most important predictors of caregiver burden were degree of disability, depression and self-efficacy following a study conducted on burden of caregivers of children with cerebral palsy in Spain. The authors concluded that it was necessary to develop interventions to reduce depression and enhance self-efficacy in parents of children with cerebral palsy as one of the primary objectives for minimizing the burden on caregivers of disabled children.

Another group of researchers in a study [1] found out that applying a designed-supportive program was capable of influencing positively the mental health status of the mothers who had children with cerebral palsy. Because of their findings, they suggested that designed-supportive programs should be applied as an effective method to promote mental health of mothers of children with cerebral palsy. In a recent study [20] aimed to reduce perceived stress levels, anxiety and depressive symptoms as well as to improve the participants' quality of life and to promote healthy dietary patterns in parents of children with cerebral palsy and motor disability living in Athens, Greece. The study eventually demonstrated that intervention which combines stress management techniques with cognitive restructuring could reduce stress.

The outcome of a study aimed to describe family distress as reported by parents of children with cerebral palsy as well as to identify factors associated with distress revealed that family distress measures were modestly associated with motor and cognitive abilities but, more strongly correlated with particular behavioral difficulties. However, the authors found activity limitations across domains to be highly associated with measures of distress. They therefore advocated for the need to monitor family functioning at intervals as the child grows and direct necessary resources to optimize child and family well-being [11].

A selective review of interventions designed to reduce stress in parents of children with intellectual disabilities with a focus on group interventions which incorporated various cognitive behavioral techniques was carried out [18]. They found out that research evidence suggested that standard service models such as respite care and case management probably helped to reduce parental stress. They also reported that there were a number of potential practical implications of reducing parental stress for maximizing the efficacy of general parent training interventions and also behavioral programs for children's challenging behaviors.

In a cross-sectional descriptive survey conducted in the Physiotherapy Department of a tertiary hospital in Nigeria, the authors found that personal problems that were experienced by parents of children with cerebral palsy included loss of job, lack of concentration at work, loss of family joy as well as derangement of financial affairs of the family. They however concluded that families caring 
for children with cerebral palsy generally had a positive attitude towards their children despite the challenges [15].

Till date, there is paucity of data on health promotion and stress management intervention for parents of cerebral palsy children in African countries especially, in Nigeria. It has been established that parents of children with cerebral palsy had experienced various degrees of psychosocial problems [11, 13 and 20]. These psychosocial problems have lots of negative impacts on the general well-being of parents of such children.

Even though, similar investigation has been done in some other countries of the world before, it is yet to be investigated in Nigerian communities to the best of the researcher's knowledge. Therefore, it is intuitive to find out the impact of mental and health promotion on parents caring for children with cerebral palsy in a developing country like Nigeria. This is with a view to implementing the findings so as to assist in reducing the stress usually being experienced by parents of such children in Nigeria in particular and the world in general. This study is therefore designed to investigate the impact of mental and health promotion on parents caring for children with cerebral palsy in Ile-Ife, Nigeria.

\section{Research questions}

The research questions for this study are as follows:

1. What impact will mental and health promotion interventions have on the stress of parents caring for children with cerebral palsy in Ile-Ife?

2. What impact will mental and health promotion interventions have on depression levels of parents caring for children with cerebral palsy in Ile-Ife?

3. Will mental and health promotion interventions have any effect on anxiety levels of parents caring for children with cerebral palsy in Ile-Ife?

\section{Research objectives}

The main objective of the study was to explore the results of a holistic mental and health promotion interventions on parents caring for children with cerebral palsy in Ile-Ife, south-west Nigeria. The specific objectives include:

- Reducing levels of stress in parents caring for children with cerebral palsy in Ile-Ife

- Reducing depressive symptoms in parents caring for children with cerebral palsy in the study area.

- Reducing anxiety levels among parents caring for children with cerebral palsy in Ile-Ife.

- Improving Quality of Life (QOL) of parents caring for children with cerebral palsy in the study area.

\section{Research hypotheses}

The following hypotheses were tested in the study:

Ho1. There will be no significant difference between groups with regards to the Anxiety and Depression subscales of Depression Anxiety Stress Scale (DASS).

Ho2. There will be no significant difference between groups regarding Perceived Stress Scale (PSS-14) score.

Ho3. There will be no significant difference between groups regarding the sociodemographic variables of respondents.

Ho4. There will be no significant difference between the mean scores of psychosocial problems before and after intervention in the experimental (intervention) group.

Ho5. There will be no significant difference between the mean scores of psychosocial problems before and after intervention in the control group.

\section{Methodology}

The study was conducted in Ile-Ife which is an ancient city located in Osun-east senatorial district of Osun State, south-west, Nigeria lying on 7.4905 degrees north and 4.5521 degrees east. The vegetation of Ile-Ife is lowland rainforest. The climate of this study area is tropical with two prominent seasons, the raining and the dry seasons. It has an area of 111 square kilometers and a 
population of 167,254 according to 2006 census. The residents are predominantly Yoruba tribe. The study is a pretest-posttest quasi-experimental design type. The parents of children with cerebral palsy who met the inclusion criteria were assigned either into the intervention group who received health promotion and stress management interventions or to the control group that received the normal existing protocol. All measurements were taken within the premises of the Department of Medical Rehabilitation, Obafemi Awolowo University Teaching Hospitals Complex, Ile-Ife. Official permission was sought from the authorities of the hospital. Prior to the commencement of the study, informed consent was sought and obtained from the subjects. Ethical clearance from the ethical clearance committee of Obafemi Awolowo University Teaching Hospitals Complex, Ile-Ife was also obtained before the commencement of data collection.

Initially, parents in both groups completed baseline measurements (pretest). Thereafter, parents in the intervention group were taken through eight weeks of health promotion and stress management interventions after when another round of posttest measurements was taken for both groups. At the end of data collection and collation, health promotion in the form of lectures was given to the parents in the control group so as to compensate them for not receiving health promotion and stress management interventions during the study. The purpose of this was to correct the temporary imbalance in health promotion and stress management benefits enjoyed by the participants in the experimental group. The sample size tor the study was calculated to be 80 for both groups. Odd and even numbers was employed to assign the parents of children with cerebral palsy who met the inclusion criteria for the study either to the intervention group or to the control group. Participants' allocation was done using their date of birth (odd or even). The total sample was split into equal halves for the intervention and the control groups.

Questionnaires: The perceived stress scale (PSS 14) was employed to assess the perceived stress levels of participants. It was employed to assess the perceived stress levels of participants. It is a selfassessment scale which measures the degree to which situations in one's life is considered stressful on a 5-point Likert scale. PSS 14 has been validated and found to have satisfactory psychometric properties in non-demented adults [1]. Reliability test was conducted using Cronbach's Alpha for test of internal consistency of the Perceived Stress Scale PSS). The reliability test result for perceived stress scale (PSS) showed a Cronbach's Alpha of 0.897.

The Depression Anxiety Stress Scale-21 (DASS-21) is a self-administered questionnaire that has three subscales to measure depression, anxiety and stress. It was also graded on a five-point Likert type scale. It has been validated in a number of populations such as Hispanic adults, American and British and found to be psychometrically sound with good reliability and validity [3, 14]. Reliability test was conducted using Cronbach's Alpha for test of internal consistency of the 'DASS'. The reliability test result for Depression, Anxiety Stress Scale (DASS) showed a Cronbach's Alpha of 0.891. The instruments were re-validated for the purpose of this study by experts in related fields and a Statistician.

The two groups were informed about the purpose of the study in the same way. They were also made to be aware that the study concerned stress and disabilities. In the intervention group, the role of the techniques for reducing stress, anxiety and depression levels were highlighted. However, the control group received the normal existing protocol. The study comprised of an eight-week stress management and lifestyle change program with weekly sessions of stress management, dietary counseling, physical exercise and psycho-education.

Initially, parents completed baseline measurements and attended a lecture on the stress system [2]. They were informed about the role of exercise, locus of control and daily routine. Parents were encouraged to keep a structured daily routine emphasizing meal times, awakening time and bedtime. The second and third meetings included training in diaphragmatic breathing using biofeedback mirror. The fourth meeting included training on cognitive restructuring and gratitude practice. During the fifth meeting, parents were informed about diet plan. The sixth meeting included training in guided imagery [8]. They were given a pen-and-paper relaxation diary to self-monitor their progress.

During the seventh meeting, parents discussed their diaries with the researcher and they were further encouraged to adhere strictly to the program. At the eight session, parents completed the final measurements [9]. Participants in the control group at the beginning and at the end of the study 
completed the same questionnaires as those in the intervention group. The period of observation of the control group was also eight weeks. Data for the study was collected using pre-tested, close-ended, questionnaires to assess the psychosocial problems of parents of children with cerebral palsy in IleIfe, south-west Nigeria. Measurements included sociodemographic variables like age, sex, educational level, number of children and marital status.

Statistical analysis was done using the Statistical Package for Social Sciences (SPSS) 21.0 program for windows. Between groups comparisons was performed. Chi-square was employed to determine significant difference in terms of sociodemographic variables between the two groups. Independent ttest was used to determine significant difference between the two groups in relation to mean scores of psychosocial problems after intervention. Paired t-test was also employed to determine if there was significant difference between mean scores of psychosocial problems before and after intervention in the experimental (intervention) group. $P$ value was set at 0.05 .

\section{Inclusion criteria}

The inclusion criteria included parent having a child diagnosed with cerebral palsy and was between the ages of 20 and 70 years. Such child was between the ages of 4 months and 10 years. Furthermore, parent was able to read, write and understand English language.

\section{Exclusion criteria}

Parents who did not meet the inclusion criteria were excluded from the study. Parents with psychiatric comorbidity, parents who were on other relaxation techniques and those that were on psychotropic medications were also excluded from the study.

\section{Results}

The age range of all the participants is between 25 and 54 years. Table 1 shows the distribution of participants in the study by age. This revealed that 31 (38.0\%) of the participants are between the age bracket of 25-34 years, 42 (52.4\%) of them are between the age bracket of 35-44 years, while 7 $(8.8 \%)$ of the total participants fall within $45-54$ years age range. Table 2 shows the distribution of all the participants by sex. From this table, it can be deduced that $9(11.2 \%)$ of the respondents were males, while the remaining $71(88.8 \%)$ were females. This shows that majority of the respondents were females. Table 3 reveals all the participants' distribution by marital status. It can be deduced that $73(91.2 \%)$ of the participants were married, $3(3.8 \%)$ of them were separated, while $4(5.0 \%)$ were widowed. This shows that majority of the participants of this study were married with none of them being single as at the time of data collection.

Table 4 shows that 30 (37.5\%) of the participants have only one child, 23 (28.7\%) of them have two children, $18(22.5 \%)$ of them have three children, while $9(11.3 \%)$ of the total participants have four children. The table also revealed that none of the sampled participants have more than 4 children. Majority of the participants $43(53.7 \%)$ had secondary school education. This can be deduced from table 5 . None of the participants was illiterate and there was none with only primary school education. However, the results shows that 27 (33.8\%) are NCE/Diploma holders, while 10 (12.5\%) among them are Degree holders.

Table 6 shows the distribution of the participants by ethnic group. It reveals that majority 74 (92.4\%) of the participants are Yoruba, $3(3.8 \%)$ of them are Hausa/Fulani, while the remaining 3 (3.8\%) of the total participants are Igbo. Table 7 shows the distribution of the participants by religion. 47 (58.7\%) of them are Christians practicing Christianity, while 33 (41.3\%) of the total participants are Muslims practicing Islam. From table 8, the intervention group had a mean (X) of 12.80 and standard deviation (SD) of 3.88, while the control group had a mean score of 7.88 and standard deviation of 5.29. From the table, df $(78), t=4.75, p<0.05$. That is, the result of $t$-value of 4.75 resulting in 0.001 significance value which is less than 0.05 alpha level. Thus, the null hypothesis earlier stated that there will be no significant difference between groups with regards to the Anxiety and Depression subscales of Depression Anxiety Stress Scale (DASS) is rejected. This implies that there is significant difference between groups with regards to the Anxiety and Depression subscales of Depression Anxiety Stress Scale (DASS) after the intervention. To determine whether there is no 
significant difference between groups regarding Perceived Stress Scale (PSS-14) score, independent ttest was used to test the null hypothesis. The result is shown in table 9: From this table, it can be deduced that there was significant difference between the intervention and control groups regarding Perceived Stress Scale (PSS-14) score after the intervention. The intervention group had a mean (X) of 43.53 and standard deviation (SD) of 4.66, while the control group had a mean score of 46.20 and standard deviation of 4.00. From the table, $\mathrm{df}(78), \mathrm{t}=-2.76, \mathrm{p}<0.05$. That is, the result of $\mathrm{t}$-value of 2.76 resulting in 0.007 significance value which is less than 0.05 alpha value. Thus the null hypothesis that there will be no significant difference between groups regarding Perceived Stress Scale (PSS-14) score is rejected. This implies that there is significant difference between groups regarding Perceived Stress Scale (PSS-14) score.

Regarding the hypothesis which stated that there will be no significant difference between groups regarding the socio-demographic variables of participants, table 10 shows the Chi-Square significance value for the cross tabulation of the participants' age against the groups (intervention and control). It can be inferred from the table that $X^{2}(2)=3.957, p>0.05$. This implies that the Chi-Square $\left(X^{2}\right)$ value of 3.957, at a degree of freedom of 2 resulted in 0.138 significance value which is greater than 0.05 alpha value of significance. Therefore, there is no significant difference between groups regarding the participants' age. That is the age of the participants that belong to the intervention group do not differ from the age of participants that participated in the control group. Table 11 shows the Chi-Square significance value for the cross tabulation of the respondents sex against the groups (intervention and control). It can be deduced from the table that $\mathrm{X}^{2}(1)=1.127, \mathrm{p}>0.05$. This implies that the Chi-Square $\left(\mathrm{X}^{2}\right)$ value of 1.127 , at a degree of freedom of 1 resulted in 0.288 significance value which is also greater than 0.05 alpha value of significance. Therefore, there is no significant difference between the groups regarding their sex. That is the sex of the respondents that belong to the intervention group do not differ from those that participated in the control group.

Table 12 shows the Chi-Square significance value for the cross tabulation of the respondents marital status against the groups (intervention and control). It can be deduced from the table that $\mathrm{X}^{2}$ $(2)=7.014, p<0.05$. This implies that the Chi-Square $\left(\mathrm{X}^{2}\right)$ value of 7.014, at a degree of freedom of 2 resulted in 0.030 significance value which is less than 0.05 alpha value of significance. Therefore, there is a significant difference between groups regarding their marital status. That is the marital status of the respondents that belong to the intervention group differs from that of respondents that participated in the control group.

Table 13 below shows the Chi-Square significance value for the cross tabulation of the respondents' number of Children against the groups (intervention and control). It can be deduced from the table that $X^{2}(3)=1.747, p>0.05$. This implies that the Chi-Square $\left(X^{2}\right)$ value of 1.747 , at a degree of freedom of 3 resulted in 0.627 significance value which is greater than 0.05 alpha value of significance. Therefore, there is no significant difference between groups regarding the participants' number of children. That is the number of children born by the respondents that belong to the intervention group do not differ from those of respondents in the control group. Table 14 shows the Chi-Square significance value for the cross tabulation of the respondents' level of education against the groups (intervention and control). It can be deduced from the table that $X^{2}(4)=3.936, p>0.05$. This implies that the Chi-Square $\left(\mathrm{X}^{2}\right)$ value of 3.936, at a degree of freedom of 4 resulted in 0.415 significance value which is greater than 0.05 alpha value of significance. Therefore, there is no significant difference between groups regarding the participants' level of education. That is the level of education of the respondents that belong to the intervention group do not differ from those of respondents in the control group.

Table 15 shows the Chi-Square significance value for the cross tabulation of the respondents religion against the groups (intervention and control). It can be deduced from the table that $\mathrm{X}^{2}(1)=$ $0.464, \mathrm{p}>0.05$. This implies that the Chi-Square $\left(\mathrm{X}^{2}\right)$ value of 0.464 , at a degree of freedom of ' 1 'resulted in 0.496 significance value which is greater than 0.05 alpha value of significance. Therefore, there is no significant difference between groups regarding the respondents' religion. That is the religion practiced by the respondents that belong to the intervention group do not differ from the religion of respondents that participated in the control group. Table 16 shows the Chi-Square significance value for the cross tabulation of the respondents ethnic group against the groups 
(intervention and control). It can be inferred from the table that $X^{2}(2)=3.387, p>0.05$. This implies that the Chi-Square $\left(\mathrm{X}^{2}\right)$ value of 3.387, at a degree of freedom of 2 resulted in 0.184 significance value which is greater than 0.05 alpha value of significance. Therefore, there is no significant difference between groups regarding their Ethnicity. That is the ethnic group of the respondents that belong to the intervention group do not differ from that of respondents that participated in the control group. From all of the above, it can be deduced that there is no significant difference generally between groups regarding the socio-demographic variables (with the exception of their marital status) of respondents.

From table 17 it can be deduced that there was a significant average difference between the pretest and posttest scores of the DASS scale in the intervention group $(t 39=12.758, \mathrm{p}<0.05)$. This implies that there is significant difference between the mean scores of the participants' psychosocial problems regarding the pre- and post-intervention scores of DASS scale in the intervention group. However, there was no significant difference found between the mean scores of participants' psychosocial problems regarding the pre-test and post-test measurements of DASS in the control group as shown in table 18. Similarly, from table 19, it can be deduced that there was a significant average difference between the pretest and posttest scores of the PSS scale in the intervention group ( $t 39=79.514, \mathrm{p}<$ 0.05). This implies that there is significant difference between the mean scores of the participants' psychosocial problems regarding the pre- and post-intervention scores of PSS scale in the intervention group.

\section{Discussion}

This study is an interventional study that evaluated the effects of an eight-week mental and health promotion program that was implemented for parents caring for children with cerebral palsy in Ile-Ife, South-West, Nigeria. Among the intervention programs are: diaphragmatic breathing, guided imagery training, progressive muscle relaxation, audio-visual material on exercise and nutrition including training on cognitive restructuring and gratitude exercises.

The age range of participants in this study was found to be between 25 and 54 years with majority (52.4\%) of them falling between the age brackets of 35 to 44 years. This finding agrees with the work of [20] where the authors reported majority (35.63\%) of their study participants to be in the age range of 26 and 41 years. This finding might be attributed to the fact that these age ranges are the usual ages of procreation for women before the age of puberty is attained. $88.8 \%$ of this study's participants were females with only $11.2 \%$ being males. This is also in line with the outcome of the study [20] which reported a higher percentage $(80 \%)$ of the participants being females. This finding can be ascribed to the fact that the care of children especially in most African countries is usually being done by the mothers, while fathers are usually saddled with financial responsibilities. The result of this study showed that majority of the participants $(91.2 \%)$ were married. This finding is also in line with the finding from [20] where $95 \%$ of the participants were married. However, this study recorded 5\% of the participants to be widowed which is contrary to the findings from [20] where there was no single widow among the participants.

With regards to number of children of each of the participants, the maximum number of each participant's children in this study was four. This is contrary to what obtained in [20] where the maximum number of participants' children was three. The recorded higher number of participants' children in this study may be due to the practice of polygamy in parts of African countries of which Nigeria is inclusive. The findings from this study further revealed higher percentage $(53.7 \%)$ of participants with secondary education. This is contrary to the very low percentage (17\%) of participants with secondary education reported by [20]. However, the two studies are in line in that none of them had participant with educational level below secondary education. The higher number of participants with secondary education in this study can be attributed to the urban nature of the study area as well as the presence of a first class tertiary institution (federal university) as well as private university and polytechnic in the city. The highest number of participants $(92.4 \%)$ are Yoruba. This finding might be due to the fact that the study area is predominantly occupied by the indigenous Yoruba people while other tribes only came to settle there for purposes of businesses and work. 
Regarding the null hypothesis which states that there will be no significant difference between groups with regards to the anxiety and depression subscales of Depression Anxiety Stress Scale, the null hypothesis was rejected as significant difference was found between groups $(t=4.75, p<0.05)$ with regards to the anxiety and depression subscales of the Depression Anxiety Stress Scale. Among the objectives of this study was to reduce anxiety and depression levels among parents of cerebral palsy children. With regards to this, the objectives were achieved. The finding is attributable to the eight-week mental and health promotion intervention programs administered on the participants in the intervention group. This finding support the work of [20] whose work similarly reported statistically significant difference between groups regarding depression and anxiety subscales of Depression Anxiety Stress Scale. The finding also support the work of [17] where the authors reported significant difference between two groups(intervention and control) in relation to mean scores of mental health after intervention $(\mathrm{P}<0.001)$.

With respect to the null hypothesis which stated that there will be no significant difference between groups in relation to the PSS, significant difference was found between the intervention and control groups $(\mathrm{t}=-2.76, \mathrm{p}<0.05)$. The objective of this study in reducing stress levels among the parents caring for children with cerebral palsy was again achieved. This result corroborate the findings of [20] whose work also reported significant difference between the intervention and control groups on Perceived Stress Scale $(r=0.79, \mathrm{p}<0.001)$. No significant difference was found between groups with regards to dimension spirituality of the Spiritual Well-Being scale $(t=-0.861, p>0.05)$. This finding can be linked to the strong adherence to spiritual believe by the people in this part of Africa whereby it is difficult to easily change their spiritual belief. This finding is in agreement with the finding of [20]. They reported no significant difference between groups with regards to dimension spirituality of Spiritual Well-Being scale $(r=0.17, p=0.178)$.

The results of the chi-square tests showed no significant difference between groups regarding participants' age $\left(X^{2}=3.957, p>0.05\right)$, sex $\left(X^{2}=1.127, p>0.05\right)$, level of education $\left(X^{2}=3.936, p>\right.$ $0.05)$, religion $\left(X^{2}=0.464, p>0.05\right)$, number of children $\left(X^{2}=1.747, p>0.05\right)$ and ethnicity $\left(X^{2}=\right.$ $3.387, \mathrm{p}>0.05$ ). What this implies is that the age, sex, level of education, religion, number of children as well as ethnicity of the participants in the intervention group did not differ from those in the control group. It was only in marital status of the participants that significant difference was found between the two groups $\left(\mathrm{X}^{2}=7.014, \mathrm{p}<0.05\right)$. The finding from this study was similar to the outcome of the work of [17] where they reported no significant difference between two groups in terms of demographic variables of the participants.

The results of the paired t-test in this study showed significant difference between pre-and postintervention mean scores of psychosocial problems of the participants in the intervention group regarding the DASS $(\mathrm{t} 39=12.758, \mathrm{p}<0.05)$ and PSS $(\mathrm{t} 39=79.514, \mathrm{p}<0.05)$. However, this type of result was not found in the control group. The outcome from the present study corroborate the results of the study by [17]. They reported significant difference between mean scores of mental health before and after intervention in the intervention (experimental) group $(\mathrm{p}<0.001)$ which was not seen in the control group.

Generally speaking, the objectives of this study were achieved. The stress, depression and anxiety levels got reduced among the parents caring for children with cerebral palsy post intervention. The realization of those objectives led to the achievement of improved quality of life (QOL) of the parents. This study has shown that intervention programs involving combinations of stress management techniques and cognitive restructuring had positive effects in reducing the levels of stress, depression and anxiety in parents caring for children with cerebral palsy. This result confirms the finding from the study [20] even though, the areas where the study was conducted differ in both studies. While this study was conducted in Nigeria, that of [20] was carried out in Athens, Greek. There was comparatively larger sample size in this study as suggested by [20] in their recommendation. The total sample size in this study was 80 as against 60 participants used in the study by [20].

Generalization of the results of this study is limited to parents who have similar sociodemographic background as the sample used in this study i.e. including parents caring for children with cerebral palsy having age between twenties and early fifties, residing in urban or rural environment but, with education level not less than secondary school education. One limitation of this study is the fact that 
the only means of monitoring compliance with the intervention programs in the intervention group was through the self-reported diary recordings which was filled by participants. The truth surrounding the self-reported recordings could not be ascertained by the researcher. Contrary to the lack of time for conducting training as well as inadequate space reported by [20], there was adequate time and well ventilated space for each training session in this study. There was a reasonable degree of consistency on the part of the participants used in this present study as against the finding by [20]. However, only two studies with similar interventions were identified in the existing literature with which to compare against the intervention programs which was implemented in this study. Some studies with other intervention programs that were found in the existing literature were referring to all caretakers of people with disabilities generally instead of specifically referring to parents caring for children with cerebral palsy. One of such studies is the one which applied stress management techniques especially mindfulness interventions to parents of disabled people which reported positive outcome regarding stress and depression level reduction [19]. Another meta-analysis study by [10] on parents of children having various developmental disorders revealed that behavioural interventions with cognitive restructuring reduced parental stress levels significantly.

\section{Conclusion}

In conclusion, this study demonstrates that mental and health promotion programs that incorporate stress management techniques coupled with cognitive re-structuring had positive impacts in reducing stress, depression and anxiety levels in parents caring for children with cerebral palsy. The study further demonstrated improved Quality of Life (QOL) of these parents which resulted from the above achievements. Therefore, implementing various mental and health promotion programs for parents caring for children with cerebral palsy by various governments and non-governmental organizations will assist greatly in reducing stress, depression and anxiety levels as well as improving the Quality of Life of such parents. This will have an overall effect of reducing the public health burden of psychosocial problems (stress, depression and anxiety) among these parents.

\section{Figures and tables}

Table 1. Distribution of participants by age ( $\mathrm{N}=80)$

\begin{tabular}{lllll}
\hline Age (Years) & Frequency & Percent & Valid Percent & Cumulative Percent \\
\hline $25-34$ & 31 & 38.8 & 38.8 & 38.8 \\
$35-44$ & 42 & 52.4 & 52.4 & 91.2 \\
$45-54$ & 7 & 8.8 & 8.8 & 100.0 \\
Total & 80 & 100.0 & 100.0 & \\
\hline
\end{tabular}

Table 2. Distribution of participants by Sex $(\mathrm{N}=80)$

\begin{tabular}{lllll}
\hline Sex & Frequency & Percent & $\begin{array}{l}\text { Valid } \\
\text { Percent }\end{array}$ & Cumulative Percent \\
\hline Male & 9 & 11.2 & 11.2 & 11.2 \\
Female & 71 & 88.8 & 88.8 & 100.0 \\
Total & 80 & 100.0 & 100.0 & \\
\hline
\end{tabular}


DOI: $10.21522 /$ TIJPH.2013.06.01.Art007

ISSN: $2520-3134$

Table 3. Distribution of participants by marital status $(\mathrm{N}=80)$

\begin{tabular}{cllll}
\hline Marital Status & Frequency & Percent & Valid Percent & Cumulative Percent \\
\hline Married & 73 & 91.2 & 91.2 & 91.2 \\
Separated & 3 & 3.8 & 3.8 & 95.0 \\
Widowed & 4 & 5.0 & 5.0 & 100.0 \\
Total & 80 & 100.0 & 100.0 & \\
\hline
\end{tabular}

Table 4. Distribution of participants by number of children $(\mathrm{N}=80)$

\begin{tabular}{cllll}
\hline No of Children & Frequency & Percent & Valid Percent & Cumulative Percent \\
\hline One & 30 & 37.5 & 37.5 & 37.5 \\
Two & 23 & 28.7 & 28.7 & 66.2 \\
Three & 18 & 22.5 & 22.5 & 88.7 \\
Four & 9 & 11.3 & 11.3 & 100.0 \\
Total & 80 & 100.0 & 100.0 & \\
\hline
\end{tabular}

Table 5. Distribution of study participants by level of education $(\mathrm{N}=80)$

Level of Education $\quad$ Frequency $\quad$ Percent Valid Percent $\quad$ Cumulative Percent

\begin{tabular}{lllll}
\hline Illiterate & 0 & 0.0 & 0.0 & 0.0 \\
Primary & 0 & 0.0 & 0.0 & 0.0 \\
Secondary & 43 & 53.7 & 53.7 & 53.7 \\
NCE/Diploma & 27 & 33.8 & 33.8 & 87.5 \\
Degree & 10 & 12.5 & 12.5 & 100.0 \\
Total & 80 & 100.0 & 100.0 & \\
\hline
\end{tabular}

Table 6. Distribution of participants by ethnic group ( $\mathrm{N}=80)$

\begin{tabular}{lllll}
\hline Ethnic Group & \multicolumn{2}{l}{ Frequency Percent } & Valid Percent & Cumulative Percent \\
\hline Yoruba & 74 & 92.4 & 92.4 & 92.4 \\
Hausa/Fulani & 3 & 3.8 & 3.8 & 96.2 \\
Igbo & 3 & 3.8 & 3.8 & 100.0 \\
Total & 80 & 100.0 & 100.0 & \\
\hline
\end{tabular}


Table 7. Distribution of participants by religion $(\mathrm{N}=80)$

Religion $\quad$ Frequency Percent Valid Percent Cumulative Percent

\begin{tabular}{lllll}
\hline Christianity & 47 & 58.7 & 58.7 & 58.7 \\
Islam & 33 & 41.3 & 41.3 & 100.0 \\
Total & 80 & 100.0 & 100.0 & \\
\hline
\end{tabular}

Table 8. Independent t-test table showing any significant difference between groups with regards to the anxiety and depression subscales of depression anxiety stress scale (DASS)

\begin{tabular}{llllllll}
\hline Groups & No & $¥$ & SD & Df & t & Sig(2-tailed) & Remark \\
\hline Intervention & 40 & 12.80 & 3.88 & & & & \\
Control & 40 & 7.88 & 5.29 & & & & Rejected \\
\hline
\end{tabular}

Table 9. Independent t-test table showing any significant difference between groups regarding perceived stress scale (PSS-14) score

\begin{tabular}{llllllll}
\hline Groups & No & $*$ & SD & Df & t & $\begin{array}{l}\text { Sig(2- } \\
\text { tailed })\end{array}$ & Remark \\
\hline Intervention & 40 & 43.53 & 4.66 & 78 & -2.76 & .007 & Rejected \\
Control & 40 & 46.20 & 4.00 & & & & \\
\hline
\end{tabular}

Table 10. Chi-Square test showing any significant difference between groups regarding the socio-demographic variable (age) of participants

\begin{tabular}{llll}
\hline & Value & df & $\begin{array}{l}\text { Asymp. Sig. (2- } \\
\text { sided) }\end{array}$ \\
\hline Pearson Chi-Square & 3.957 & 2 & .138 \\
Likelihood Ratio & 4.348 & 2 & .114 \\
Linear-by-Linear Association & 2.052 & 1 & .152 \\
N of Valid Cases & 80 & & \\
\hline
\end{tabular}

Table 11. Chi-Square test showing any significant difference between groups regarding the socio-demographic variable (Sex) of participants.

\begin{tabular}{lccl}
\hline & Value & df & Asymp. Sig. (2-sided) \\
\hline Pearson Chi-Square & 1.127 & 1 & .288 \\
Continuity Correction $^{\mathrm{b}}$ & .501 & 1 & .479 \\
Likelihood Ratio & 1.146 & 1 & .284 \\
Fisher's Exact Test & & &
\end{tabular}


DOI: $10.21522 /$ TIJPH.2013.06.01.Art007

ISSN: $2520-3134$
Linear-by-Linear Association
1.113
1
.292
$\mathrm{N}$ of Valid Cases
80

Table 12. Chi-Square test showing any significant difference between groups regarding the socio-demographic variable (Marital Status) of participants.

\begin{tabular}{llll}
\hline & Value & df & Asymp. Sig. (2-sided) \\
& & & \\
\hline Pearson Chi-Square & 7.014 & 2 & .030 \\
Likelihood Ratio & 9.718 & 2 & .008 \\
Linear-by-Linear Association & 2.210 & 1 & .137 \\
N of Valid Cases & 80 & & \\
\hline
\end{tabular}

Table 13. Chi-Square test showing the significant difference between groups regarding the socio-demographic variable (Number of Children) of respondents

\begin{tabular}{lccc}
\hline & Value & df & Asymp. Sig. (2-sided) \\
\hline Pearson Chi-Square & 1.747 & 3 & .627 \\
Likelihood Ratio & 1.768 & 3 & .622 \\
Linear-by-Linear Association & .047 & 1 & .828 \\
N of Valid Cases & 80 & & \\
\hline
\end{tabular}

Table 14. Chi-Square test showing any significant difference between groups regarding the socio-demographic variable (Level of Education) of respondents.

\begin{tabular}{llll}
\hline & Value & df & Asymp. Sig. (2-sided) \\
\hline Pearson Chi-Square & $3.936^{\mathrm{a}}$ & 4 & .415 \\
Likelihood Ratio & 4.718 & 4 & .317 \\
Linear-by-Linear Association & 2.975 & 1 & .085 \\
N of Valid Cases & 80 & & \\
\hline
\end{tabular}

Table 15. Chi-Square test showing any significant difference between groups regarding the socio-demographic variable (Religion) of respondents

\begin{tabular}{|c|c|c|c|}
\hline & Value & $\mathrm{df}$ & Asymp. Sig. (2-sided) \\
\hline Pearson Chi-Square & .464 & 1 & .496 \\
\hline Continuity Correction ${ }^{\mathrm{b}}$ & .206 & 1 & .650 \\
\hline Likelihood Ratio & .465 & 1 & .495 \\
\hline \multicolumn{4}{|l|}{ Fisher's Exact Test } \\
\hline $\begin{array}{l}\text { Linear-by-Linear } \\
\text { Association }\end{array}$ & .458 & 1 & .498 \\
\hline $\mathrm{N}$ of Valid Cases & 80 & & \\
\hline
\end{tabular}


Table 16. Chi-Square test showing the significant difference between groups regarding the socio-demographic variable (ethnic group) of respondents

\begin{tabular}{llll}
\hline & Value & df & Asymp. Sig. (2-sided) \\
\hline Pearson Chi-Square & 3.387 & 2 & .184 \\
Likelihood Ratio & 4.553 & 2 & .103 \\
Linear-by-Linear Association & .071 & 1 & .790 \\
N of Valid Cases & 80 & & \\
\hline
\end{tabular}

Table 17. Paired t-test to determine any significance difference between the mean scores of DASS scale in the intervention group before and after intervention.

\begin{tabular}{|c|c|c|c|c|c|c|c|c|}
\hline & \multicolumn{5}{|c|}{ Paired Differences } & \multirow[t]{3}{*}{$\mathrm{t}$} & \multirow[t]{3}{*}{$\mathrm{df}$} & \multirow{3}{*}{$\begin{array}{l}\text { Sig. } \\
\text { (2- } \\
\text { tailed) }\end{array}$} \\
\hline & \multirow[t]{2}{*}{ Mean } & \multirow[t]{2}{*}{$\begin{array}{l}\text { Std. } \\
\text { Deviation }\end{array}$} & \multirow[t]{2}{*}{$\begin{array}{l}\text { Std. } \\
\text { Error } \\
\text { Mean }\end{array}$} & \multicolumn{2}{|c|}{$\begin{array}{l}95 \% \text { confidence } \\
\text { interval of the } \\
\text { Difference }\end{array}$} & & & \\
\hline & & & & Lower & Upper & & & \\
\hline $\begin{array}{l}\text { Intervention } \\
\text { pretest } \\
\text { (DASS)- } \\
\text { Intervention } \\
\text { posttest } \\
\text { (DASS) }\end{array}$ & 8.8375 & 5.08286 & .56828 & 6.11887 & 11.55613 & 12.758 & 39 & .000 \\
\hline
\end{tabular}

Table 18. Paired t-test to determine any significance difference between the mean scores of DASS scale in the control group

\begin{tabular}{|c|c|c|c|c|c|c|c|c|}
\hline & \multicolumn{5}{|c|}{ Paired Differences } & \multirow[t]{3}{*}{$\mathrm{t}$} & \multirow[t]{3}{*}{$\mathrm{df}$} & \multirow{3}{*}{$\begin{array}{l}\text { Sig. } \\
\text { (2- } \\
\text { tailed) }\end{array}$} \\
\hline & \multirow[t]{2}{*}{ Mean } & \multirow[t]{2}{*}{$\begin{array}{l}\text { Std. } \\
\text { Deviation }\end{array}$} & \multirow[t]{2}{*}{$\begin{array}{l}\text { Std. } \\
\text { Error } \\
\text { Mean }\end{array}$} & \multicolumn{2}{|c|}{$\begin{array}{l}\text { 95\% confidence } \\
\text { interval of the } \\
\text { Difference }\end{array}$} & & & \\
\hline & & & & Lower & Upper & & & \\
\hline $\begin{array}{l}\text { Control pretest } \\
\text { (DASS)-Control } \\
\text { posttest (DASS) }\end{array}$ & 1.2889 & 3.06276 & .56828 & 3.11887 & 4.55613 & 6.758 & 39 & .0685 \\
\hline
\end{tabular}

Table 19. Paired t-test to determine any significance difference between the mean scores of PSS scale in the intervention group before and after intervention.

\begin{tabular}{|c|c|c|c|c|c|c|c|c|}
\hline & \multicolumn{5}{|c|}{ Paired Differences } & \multirow[t]{3}{*}{$\mathrm{t}$} & \multirow[t]{3}{*}{ df } & \multirow{3}{*}{$\begin{array}{l}\text { Sig. } \\
(2- \\
\text { tailed })\end{array}$} \\
\hline & \multirow[t]{2}{*}{ Mean } & \multirow[t]{2}{*}{$\begin{array}{l}\text { Std. } \\
\text { Deviation }\end{array}$} & \multirow[t]{2}{*}{$\begin{array}{l}\text { Std. } \\
\text { Error } \\
\text { Mean }\end{array}$} & \multicolumn{2}{|c|}{$\begin{array}{l}\text { 95\% confidence } \\
\text { interval of the } \\
\text { Difference }\end{array}$} & & & \\
\hline & & & & Lower & Upper & & & \\
\hline $\begin{array}{l}\text { Intervention } \\
\text { pretest } \\
\text { (PSS)- } \\
\text { Intervention } \\
\text { posttest } \\
\text { (PSS) }\end{array}$ & 10.4225 & 4.54729 & .50840 & 4.43195 & 16.41305 & 79.514 & 39 & .000 \\
\hline
\end{tabular}


DOI: $10.21522 /$ TIJPH.2013.06.01.Art007

ISSN: $2520-3134$

\section{References}

[1].Ali E., Julie J., Mindy J.K., Martin J.S., Molly E.Z. and Richard B.L. (2014). Validation of the Perceived Stress Scale in a community sample of older adults. Int J Geriatr Psychiatry, 29 (6), 645-652. Doi: 10. 1002/gps.4049.

[2].April A. K., Dharani B., and Peters K. (2012). Impact of Locus of Control Expectancy on Level of WellBeing. Review of European Studies, 4, 124-137.

[3].Crawford J.R and Henry J.D. (2003). The Depression Anxiety Stress Scales (DASS): Normative data and latent structure in a large non-clinical sample. British Journal of Clinical Psychology, 42:11-131.

[4].Donald K.A., Sandra P., Angelina K. and Bearden D. (2014). Pediatric Cerebral Palsy in Africa: A Systematic Review. Semin Pediatr Neurol, 30-35.

[5].El-Tallawy H.N., Farghaly M.A., Shehata G.A., Rageh T.A., Metwally N.A., Badry R, Sayed A.M., Abd El Hamed M., Abd-Elwarth A., Kandil M.R. (2014). Cerebral palsy in Al-Quseir City, Egypt: prevalence, subtypes, and risk factors. Neuropsychiatric Disease and Treatment, 10, 1267-1272.

[6].Gulam K., Hayley S., Johurul I., Monzurul A., Jenny J., Iona N., Robert B., Cheryl J., Nadia B. and Mohammad M. (2015). Bangladesh Cerebral Palsy Register (BCPR): a pilot study to develop a national cerebral palsy (CP) register with surveillance of children for CP. BMC Neurol, 15, 173.

[7].Hodapp M. R. (1998). Advancing Finding, Theories, and Methods Concerning Children with Disabilities. Athens: Cambridge University Press. http://www.KeepKidHealthy.com.

[8].Jacobson E. (1938). Progressive Relaxation. Chicago: University of Chicago Press.

[9].Jerath R., Edry J.W., Barnes V.A., Jerath V. (2006). Physiology of long pranayamic breathing: neural respiratory elements may provide a mechanism that explains how slow deep breathing shifts the autonomic nervous system. Med Hypotheses, 67(3), 566-571.

[10]. Jones J. and Jennifer P. (2005). Family Adaptation, Coping and Resources: Parents of Children with Developmental Disabilities and Behaviour Problems. Journal on Developmental Disabilities, 11, 31-46.

[11]. Majnemer A, Shevell M, Law M, Poulin C, Rosenbaum P. (2012). Indicators of distress in families of children with cerebral palsy. Disabil Rehabil, 34(14), 1202-1207.

[12]. Marrón, E. M., Redolar-Ripoll D., Boixadós M., Nieto, R., Guillamón N., Hernández E. (2013). Burden on caregivers of children with cerebral palsy: Predictors and related factors. Universitas Psychologica, 12(3), 767777.

[13]. Nimbalkar S., Raithatha S., Shah R., Panchal D.A. (2014). A Qualitative Study of Psychosocial Problems among Parents of Children with Cerebral Palsy Attending Two Tertiary Care Hospitals in Western India. ISRN Family Med, doi: 10.1155/2014/769619.

[14]. Norton P.J. (2007). Depression Anxiety and Stress Scales (DASS-21): psychometric analysis across four racial groups. Anxiety Stress Coping. 20(3), 253-65.

[15]. Olawale O.A, Abraham N.D. and Raphael K.K. (2013). Psychological impact of cerebral palsy on families: The African perspective. J Neurosci Rural Pract, 4(2), 159-163.

[16]. Ozmen M., Caliskan M., Apak S., Gokcay G. (1993). 8-Year clinical experience in cerebral palsy. J Trop Pediatr, 39, 52-54.

[17]. Parvinian A.M, Kermanshahi S.M., Sajedi F. (2012). The Effect of a supportive program on mental health of mothers of children with cerebral palsy. http://osub.mums.ac.ir/osub/nilfr/nmjournal/index.php.

[18]. Richard P.H. and Alexandra B. (2004). Practitioner review: Stress intervention for parents of children with intellectual disabilities. Journal of Child Psychology and Psychiatry, 45(8), 1338-1349.

[19]. Singer GH, Ethridge BL and Aldana SI (2007). Primary and secondary effects of parenting and stress management interventions for parents of children with developmental disabilities: a meta-analysis, Ment Retard Dev Disabil Res Rev, 13 (4): 357-369.

[20]. Thanou E., Tsiou C., Kattami, C., Chrousos, G. P., \& Darviri, C. (2016). A Stress Management and Health Promotion Intervention for Parents of Children with Cerebral Palsy and Motor Disability at the Infant Department of the Greek Center for the Protection and Rehabilitation of the Disabled (ELEPAP). QuasiExperimental study. Psychology, 7, 557-564. 